\title{
The mediating role of prenatal depression in adult attachment and maternal-fetal attachment in primigravida in the third trimester
}

\author{
Ling Zhang ${ }^{1}$, Lei Wang ${ }^{1}$, Qiuyu Yuan ${ }^{1}$, Cui Huang ${ }^{1}$, Shu Cui ${ }^{1}$, Kai Zhang ${ }^{2^{*}}$ and Xiaoqin Zhou ${ }^{2^{*}}$
}

\begin{abstract}
Background: Prenatal depression and adult attachment are factors that affect the establishment of an intimate relationship between a mother and fetus. The study explored differences in prenatal depression and maternal-fetal attachment (MFA) scores between different types of adult attachment and the effects of maternal depression scores and attachment dimensions on maternal intimacy with the fetus.

Methods: The Edinburgh Postnatal Depression Scale (EPDS), Experience of Close Relationship (ECR) scale, Maternal Antenatal Attachment Scale (MAAS) and a general data scale were used to investigate 260 primigravida. An exploratory analysis was performed to analyze the effects of the depression score and adult attachment on MFA.

Results: The results showed that pregnant women with insecure attachment exhibited an increased prevalence of prenatal depression, lower total MFA scores, and lower MFA quality compared with those women with secure adult attachment. The explorative analysis showed that the depression scores mediated the relationship between adult attachment avoidance and MFA quality.

Conclusions: Primigravida who had insecure adult attachment exhibited an increased prevalence of prenatal depression and lower MFA. Maternal depression and adult attachment may affect the emotional bond between a mother and fetus. This finding should be seriously considered, and timely intervention needs to take personality traits into consideration.
\end{abstract}

Keywords: Prenatal depression, Primigravida, Adult attachment dimension, Maternal-fetal attachment

\section{Background}

Pregnancy is a significant and arduous process that can be extremely challenging for a woman physiologically and psychologically. The prevalence of perinatal depression in the Chinese population ranges between 15 and $20 \%$ [1], and the prevalence among women in low- and middle-income countries/regions is significantly higher [2]. A systematic review involving 48,904 persons from

\footnotetext{
* Correspondence: zhangkai@ahmu.edu.cn; zhouxqlulu@126.com ${ }^{2}$ Chaohu Hospital, Anhui Medical University, Hefei 238000, China Full list of author information is available at the end of the article
}

20 low-income middle-income countries reported that the prevalence of depression was $25.3 \%$ prenatally [3]. Prenatal depression not only affects the mood of pregnant women, such as increasing the risk of suicide and the prevalence of postpartum depression $[4,5]$, but also affects the development of the fetus [6,7], and even increases the risk of mental health issues in the child [8]. Moreover, prenatal depression can significantly predict the degree of attachment of pregnant women to the fetus $[9,10]$ and even affect the intimate bond with the child after pregnancy [11].

(C) The Author(s). 2021 Open Access This article is licensed under a Creative Commons Attribution 4.0 International License, which permits use, sharing, adaptation, distribution and reproduction in any medium or format, as long as you give appropriate credit to the original author(s) and the source, provide a link to the Creative Commons licence, and indicate if changes were made. The images or other third party material in this article are included in the article's Creative Commons licence, unless indicated otherwise in a credit line to the material. If material is not included in the article's Creative Commons licence and your intended use is not permitted by statutory regulation or exceeds the permitted use, you will need to obtain permission directly from the copyright holder. To view a copy of this licence, visit http://creativecommons.org/licenses/by/4.0/ The Creative Commons Public Domain Dedication waiver (http://creativecommons.org/publicdomain/zero/1.0/) applies to the data made available in this article, unless otherwise stated in a credit line to the data. 
Maternal-fetal attachment (MFA) is the mother's emotional connection to the fetus and is an important indication of whether the pregnant mother can adapt to changes in pregnancy and assume maternal responsibility [12]. MFA increases with gestational age and stabilizes in the third trimester [13]. In addition, MFA can predict the postpartum mental status of mothers, such as the presence of anxiety and depression, and affect the postpartum mother-infant attachment quality [14]. Pregnant women with weak MFA are less likely to engage in health promotion activities and are more likely to have an unhealthy newborn than those with strong MFA [8].

Moreover, a significant positive correlation is noted between MFA and neonatal outcome during pregnancy [15]. In addition, the level of MFA can predict children's development of early behavioral and emotional ability [16]. Furthermore, a couple's relationship is among the most important predictors of MFA in addition to the mental health of pregnant women [17]. The mental health of her partner affects how a pregnant woman feels about the fetus. For example, when a partner's childcare pressure is high, the intimate relationship between a woman and her child during the perinatal period will decrease [18]. In addition to prenatal depression, many factors are predictors of MFA, such as the gestational age, social support and prenatal testing [19]. In addition, education level, obstetric problems during pregnancy, duration of pregnancy, socioeconomic status, fertility attitude, and fetal awareness are factors that affect MFA [20, 21]. The personality characteristics of pregnant women, such as adult attachment, can also affect MFA.

Attachment is defined as an emotional connection between an individual and their primary caregiver during the earliest stage of life [22]. Attachment behavior forms an internal working model during individual development. Adult attachment is the continuation and reappearance of early attachment experience. When people encounter difficulties or significant changes in life, such as pregnancy [23], the internal working model is activated and manifested in different ways, eliciting emotional and behavioral responses. Adult attachment plays an acknowledged role in maternal mental health [24]. Catherine's quality-stress model showed that relationship templates dominated by fear or lack of security, such as insecure attachment, may become a personality trait rendering women more vulnerable to perinatal depression than those without this trait [25]. The level of prenatal attachment affects maternalinfant attachment after delivery [26]. In a recent study by Huang and colleagues, women with greater adult attachment anxiety and avoidance exhibited more symptoms of depression [27].

Studies have shown that primiparas have a higher incidence of prenatal depression and anxiety scores after pregnancy than multiparas [28]. Due to the lack of fertility experience and low sense of self-efficacy in parenting [29], there are certain obstacles to their development of the mother-fetal relationship, indicating that special attention should be paid to primiparas.

Taken together, prenatal depression, MFA and adult attachment all are related. A previous study indicated that depression partially mediated the connection between insecure attachment and mother-infant attachment after birth [30]. Additionally, the regulatory role of postpartum depression symptoms in the relationship between different attachment types and postpartum bonding has been confirmed [31]. However, the role of maternal depression and two dimensions of attachment (avoidance and anxiety) in MFA during pregnancy are currently unknown. This article aimed to explore the difference between prenatal depression and MFA in pregnant women with different attachment styles and the role of maternal depression and attachment on MFA in primiparas. More specifically, we predicted that maternal depression mediates the relationship between the two dimensions of attachment and MFA.

\section{Methods}

\section{Procedure and participants}

The data were collected at the antenatal clinic of Chaohu Hospital of Anhui Medical University. The hospital is a comprehensive tertiary hospital that provides medical services to approximately one million people. The average number of deliveries in the hospital is approximately 2000 per year. The inclusion criteria were as follows: 1) primigravida; 2) pregnant women aged 18-45 years; 3$)$ women with a gestational age of $28-40$ weeks; and 4) women with a singleton gestation. The exclusion criteria were as follows: 1) a previous history of mental illness; 2) a high-risk pregnancy (gestational diabetes, hypertension and preeclampsia); and 3) a history of miscarriage.

Before the start of the study, three graduate students and two nurses received unified standardized training regarding the entire research process, the precautions necessary while completing the self-made general information questionnaire, and the unified instructions of each scale. The training time was approximately two weeks. Data collection was based on convenience sampling along with probability sampling. We randomly selected the time from September to December 2019 to collect samples. According to the pregnant women's consultation number, those with an odd number of consultation numbers were randomly selected to fill out all the scales. Finally, according to the inclusion and exclusion criteria, a total of 260 samples that met the criteria were included. Before completing the questionnaire, all participants were instructed by standardized and 
uniformly trained staff. Approximately ten minutes were required to complete all questionnaires. The ethics committee of Chaohu Hospital of Anhui Medical University approved the study protocol. The procedures used in this study adhered to the principles of the Declaration of Helsinki. All women signed informed consent forms before participating in this study.

\section{Measures}

\section{Demographic characteristics}

We used a self-designed questionnaire to collect the demographic characteristic data, including age, gestational age, education level, planned pregnancy, prenatal education, working status, exercise, and marital satisfaction of the pregnant women enrolled in our study (the specific content of the self-designed questionnaire is shown in the supplementary material file).

\section{Prenatal depression}

The Edinburgh Postpartum Depression Scale (EPDS) [32] was chosen to assess the participants' severity of depression. The EPDS can be used to screen for postpartum depression as well as depression during pregnancy. The EPDS contains a total of 10 items. The total score ranges from 0 to 30 , and the higher the score is, the more serious the degree of depression. Cronbach's alpha was 0.78 and test-retest reliability was 0.90 [33]. We used a cut-off of $\geq 12$ in this study. We used the Chinese version of the EPDS, which has been verified and frequently used in previous studies [34-36].

\section{Adult attachment}

Adult attachment in all pregnant women was assessed with the Experience of Close Relationship (ECR) scale [37], which has demonstrated high measurement accuracy [38]. The reliability and validity of this scale have been tested in China [39], and it has been used in the Chinese population [40]. The scale consists of 36 items, each ranging from 1 "strongly disagree" to 7 "strongly agree". The scale has the following two dimensions: anxiety and avoidance. The avoidance subscale includes 18 items, indicating the avoidance of intimacy and interdependence. The anxiety subscale also includes 18 items and indicates concerns about exclusion and abandonment. According to the score of the two dimensions, adult attachment can be divided into secure and insecure attachment, and there are three types of insecure styles (attentive, indifferent and phobic).

\section{MFA}

The Maternal Antenatal Attachment Scale (MAAS) [41] was used to assess the MFA of the participants. The reliability and validity of this scale have been tested in Chinese pregnant women [42]. The MAAS is a self-reported scale that includes 19 questions with a 5-point scoring system, and the total MFA score ranges from 5 to 95 , with higher score signifying higher MFA [43]. The scale includes the following two sub-dimensions: "MFA quality" (items 3, 6, 9, 10,11, 12, 13, 15, 16, and 19) and "MFA intensity" (items 1, 2, 4, 5, 8, 14, 17, and 18). Item 7 is only included in the total score and does not affect any of these two dimensions. The MFA quality indicates the emotional experience with regard to the fetus, and the MFA intensity indicates the time and energy devoted to the fetus by the pregnant women.

\section{Data analysis}

We used the Statistical Package for Social Sciences (IBM SPSS 22.0) for all analyses conducted in this study. The continuous variables were tested by t-test or MannWhitney $U$ test according to whether they exhibited a normal distribution, and the chi-square test was used to classify the variables. Before the mediation analysis, Spearman's correlation was calculated to determine the correlations between attachment anxiety/avoidance, the maternal depression score, and MFA. Finally, we found pairwise correlations between anxiety/avoidance, the depression score, and the MFA quality. Subsequently, model 4 of Hayes's PROCESS macro and Bootstrap were used to analyze the mediating effect [44]. The model estimates the direct effect of anxiety/avoidance on maternal depression and maternal depression on MFA, the indirect effect of attachment anxiety/avoidance on MFA mediated by maternal depression as well as the direct effect of on MFA. A $p$-value of 0.05 was considered to be statistically significant.

\section{Results}

\section{Demographic characteristics of the participants}

Two hundred and sixty pregnant women were enrolled in our study. The mean age of the pregnant women was $26.52(\mathrm{SD}=3.18)$ years, and the mean gestational age was 35.57 ( $\mathrm{SD}=2.57$ ) weeks. Among all participants, $54.23 \%$ of the pregnant women had secure adult attachment. Most women had a high school or junior college diploma (51.93\%), and those with an education level of junior high school or lower and bachelor's degree or higher accounted for 16.15 and $31.92 \%$ of the total, respectively. Moreover, $71.15 \%$ of the participants had a planned pregnancy, and $64.23 \%$ of the participants received prenatal education during pregnancy. In addition, $59.62 \%$ of the pregnant women were employed. When asked whether they exercised during the pregnancy period, $71.15 \%$ of the pregnant women said yes. Additionally, $84.23 \%$ of the participants reported that they were satisfied with their marriage. Our results also showed that in total, $18.85 \%$ of the pregnant women had a score of 12 or greater, indicating prenatal depression. 
The proportion of women with low MFA (Total MAAS $\leq 75$ ) was $55 \%$. The mean total MFA score was 74.12 (SD = 7.32), and the mean MFA intensity and MFA quality were $28.21(\mathrm{SD}=4.62)$ and 42.14 $(\mathrm{SD}=4.57)$, respectively.

\section{Differences in the demographic characteristics, prenatal depression and MFA between the secure and insecure groups}

As shown in Table 1, compared with the secure group, the prevalence of depression was increased in the insecure group $(25.21 \%$ vs $13.48 \%, p=0.016)$. The EPDS score was also higher in the insecure group $(8.64 \pm 4.47$ vs $6.99 \pm 4.24, p=0.003)$. In addition, the proportion of women with low MFA was higher in the insecure group $(62.18 \%$ vs $48.94 \%, p=0.032)$. Furthermore, the results suggested that the total MFA score and MFA quality in the insecure group were both lower than those in the secure group $(72.87 \pm 7.14$ vs $75.17 \pm 7.33, p<0.001$, $41.34 \pm 4.48$ vs $42.82 \pm 4.54, p=0.003)$. Moreover, no differences in the demographic characteristics and MFA intensity were noted between the two groups (all $p>$ 0.05).

\section{Explorative analysis}

To determine the relationship among the variables of the EPDS score, two dimensions of adult attachment (avoidance and anxiety) and MFA, Spearman's correlation analyses were performed (Table 2). As shown in Table 2, both avoidance and anxiety were correlated with the EPDS score and the MFA quality (all $p<0.05$ ), and the EPDS score was correlated with the MFA quality. Based on these results, an SPSS process script was used to analyze the mediating role of the EPDS score in the relationship between avoidance (anxiety) and the MFA quality. However, there was only a significant indirect effect of avoidance on the MFA quality through depression $\quad(\mathrm{b}=-0.2474, \quad \mathrm{SE}=0.1175, \quad 95 \% \quad \mathrm{CI}=[-$ $0.5438--0.0691])$. Figure 1 shows the coefficients of the relationships among the independent, mediating, and outcome variables.

\section{Discussion}

This is the first study on the associations between of attachment and EPDS score on MFA in primigravida to the best of our knowledge. The transition to motherhood implies great changes in the role and life of pregnant women; thus, helping pregnant women through pregnancy can promote a good pregnancy outcome. These results are helpful for understanding the influence of adult attachment and depression on MFA.

In our study, in total, $18.85 \%$ of the participants suffered from prenatal depression, which was lower than the incidence reported in another study involving Chinese primipara in late pregnancy [45]. A possible explanation is a difference in the prenatal depression screening scale used, and another possible explanation might be the difference in the demographic data. A study conducted in South African showed that the prevalence of prenatal depression was $21 \%$ [46]. The prevalence of

Table 1 Demographic characteristics, prenatal depression and MFA between the secure and insecure groups

\begin{tabular}{|c|c|c|c|c|c|c|}
\hline & \multicolumn{2}{|c|}{$\begin{array}{l}\text { All participants } \\
(n=260)\end{array}$} & $\begin{array}{l}\text { Secure } \\
(n=141 ; 54.23 \%)\end{array}$ & $\begin{array}{l}\text { Insecure } \\
(n=119 ; 45.77 \%)\end{array}$ & $t / Z / X^{2}$ & $\mathbf{P}$ \\
\hline Age (years) & \multicolumn{2}{|c|}{$26.52 \pm 3.18$} & $26.66 \pm 3.03$ & $26.34 \pm 3.37$ & -1.020 & 0.308 \\
\hline Gestational weeks & \multicolumn{2}{|c|}{$35.57 \pm 2.57$} & $35.37 \pm 2.73$ & $35.81 \pm 2.35$ & -0.1056 & 0.291 \\
\hline \multicolumn{7}{|l|}{ Education } \\
\hline High school or lower & & $42(16.15 \%)$ & $19(13.48 \%)$ & $23(19.33 \%)$ & \multirow[t]{3}{*}{4.893} & \multirow[t]{3}{*}{0.087} \\
\hline High school or junior college & & 135 (51.93\%) & $82(58.16 \%)$ & $53(44.54 \%)$ & & \\
\hline Bachelor degree or higher & & $83(31.92 \%)$ & $40(28.37 \%)$ & $43(36.13 \%)$ & & \\
\hline Planned pregnancy & Yes & $185(71.15 \%)$ & $98(69.50 \%)$ & $87(73.11 \%)$ & 0.409 & 0.523 \\
\hline Prenatal education & Yes & 167 (64.23\%) & $95(67.38 \%)$ & $72(59.66 \%)$ & 1.326 & 0.249 \\
\hline Employed & Yes & $155(59.62 \%)$ & $57(50.00 \%)$ & $98(82.35 \%)$ & $<0.001$ & 0.988 \\
\hline Exercise & Yes & $185(71.15 \%)$ & $98(69.50 \%)$ & $87(73.11 \%)$ & 0.409 & 0.523 \\
\hline Marital satisfaction & Yes & $219(84.23 \%)$ & $123(87.23 \%)$ & $96(80.67 \%)$ & 2.092 & 0.148 \\
\hline Prenatal depression & Yes & $49(18.85 \%)$ & $19(13.48 \%)$ & $30(25.21 \%)$ & 5.811 & 0.016 \\
\hline EPDS score & \multicolumn{2}{|c|}{$7.75 \pm 4.14$} & $6.99 \pm 4.24$ & $8.64 \pm 4.47$ & -2.922 & 0.003 \\
\hline Low MFA & \multicolumn{2}{|c|}{$143(55 \%)$} & $69(48.94 \%)$ & $74(62.18 \%)$ & 4.577 & 0.032 \\
\hline Total score of MFA & \multicolumn{2}{|c|}{$74.12 \pm 7.32$} & $75.17 \pm 7.33$ & $72.87 \pm 7.14$ & 2.548 & $<0.001$ \\
\hline MFA intensity & \multicolumn{2}{|c|}{$28.21 \pm 4.62$} & $28.49 \pm 4.39$ & $27.87 \pm 4.87$ & -1.533 & 0.125 \\
\hline MFA quality & \multicolumn{2}{|c|}{$42.14 \pm 4.57$} & $42.82 \pm 4.54$ & $41.34 \pm 4.48$ & -2.992 & 0.003 \\
\hline
\end{tabular}


Table 2 Correlation analysis results of each variable

\begin{tabular}{|c|c|c|c|c|c|c|}
\hline Variable & EPDS score & Avoidance & Anxiety & Total score of MFA & MFA intensity & MFA quality \\
\hline EPDS score & 1.000 & & & & & \\
\hline Avoidance & $0.171^{* *}$ & 1.000 & & & & \\
\hline Anxiety & $0.330^{* *}$ & $0.245^{* *}$ & 1.000 & & & \\
\hline Total score of MFA & -0.044 & $-0.192^{* *}$ & -0.023 & 1.000 & & \\
\hline MFA intensity & 0.101 & -0.143 & 0.059 & $0.835^{* *}$ & 1.000 & \\
\hline MFA quality & $0.235^{* *}$ & $-0.194^{* *}$ & $-0.144^{*}$ & $0.794^{* *}$ & $0.410^{* *}$ & 1.000 \\
\hline
\end{tabular}

Legend: ${ }^{*} p<0.05,{ }^{* *} p<0.01$

prenatal depression was $27.5 \%$ among Turkish Women [47], $10.0 \%$ during late pregnancy in the Netherlands [48], 14.8\% in Spain [49], and 6.1\% in the US [50]. These results also indicate that there are differences in the prevalence of prenatal depression among pregnant women from different cultures.

We found that women with secure adult attachment had a lower prevalence of prenatal depression. A pregnant woman's attachment patterns continue to affect her experience during pregnancy, increasing the risk of mood disorders during pregnancy [25]. Individuals with secure adult attachment seek social support to regulate negative emotions when needed [51]. Moreover, pregnant women with secure adult attachment reported a lower proportion of low MFA, a high total MFA score and a high MFA quality. A study involving 165 pregnant women in Poland also found that maternal attachment affects women's image as a mother and their connection with their fetus [52], and people with secure adult attachment are more likely to assume the role of parents [23]. Therefore, prenatal intervention can be performed in terms of the personality structure of the pregnant women, such as adult attachment. A previous study also noted that it is necessary to screen for attachment styles and provide tailored care during pregnancy [53]. But there was no difference in MFA intensity between the secure attachment and the insecure attachment groups. Studies have also pointed out that the quality of maternal-fetal attachment is affected by attachmentrelated avoidance, while the intensity of maternal-fetal attachment is not affected by adult attachment, which also showed that the intensity and quality dimensions need to be addressed individually [17].

Further analysis revealed that maternal attachment avoidance and anxiety were negatively related to the MFA quality, which is consistent with previous research results [54]. Self-reported romantic attachment predicts high avoidance scores using the parental role scale in pregnant women, and these women may face difficulties in developing their maternal identity [52]. Those who attached great importance to adult attachment avoidance felt uncomfortable with intimacy and invalidated the attachment system [55]. Women with high avoidance may regard pregnancy and the fetus as sources of pain and, thus, adopt a strategy of alienating the fetus and avoiding emotional involvement [56]. As a result, the emotional experience with regard to the fetus may be relatively low. In addition, people with high adult attachment anxiety are afraid of rejection. Thus, these individuals may think that they do not have the ability to cultivate intimate relationships and pay more attention to their own distress and attachment needs $[57,58]$. There was also a negative correlation between depression during pregnancy and the MFA quality. Previous research also revealed

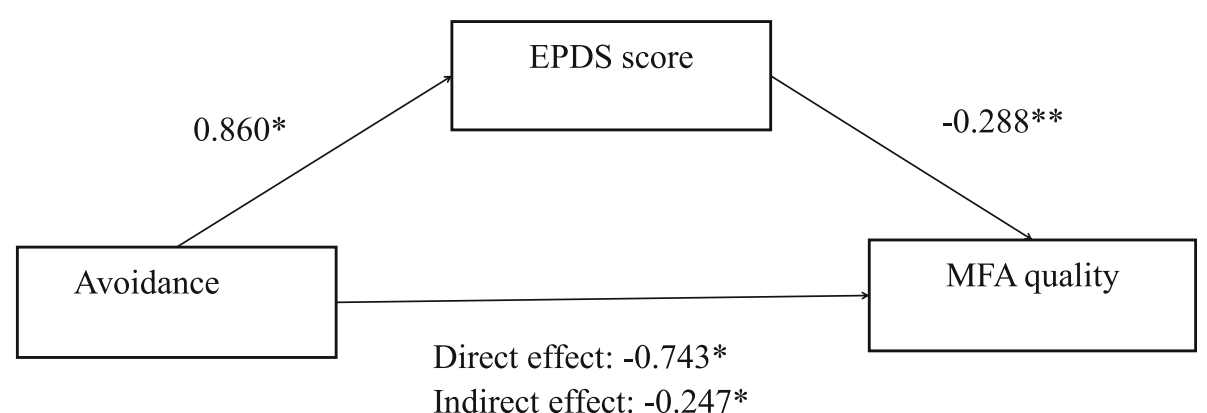

Fig. 1 Results of mediating analysis showing associations between avoidance (independent variable), EPDS score (mediator), and MFA quality (outcome variable). Legend: EPDS, Edinburgh Postnatal Depression Scale; ${ }^{*} p<0.05,{ }^{* *} p<0.01$ 
that pregnant women with depression were less sensitive to the fetus [59] and that depression during pregnancy was also a risk factor for poor MFA [12].

The exploratory mediation analysis revealed that low maternal adult attachment avoidance directly and indirectly reduced the MFA quality score through the prenatal depression score. The results suggested that an avoidance attitude toward the attachment subjects rendered the women susceptible to the interference of depression symptoms, reducing emotional investment in the fetus. A possible mechanism is that the internal working model of attachment has an important impact on an individual's cognition, emotion, and behavior with regard to interpersonal communication, and the avoidance attachment model formed in childhood leads to a sense of mistrust of others in pregnant women. This internal working model is triggered by stressful events, such as pregnancy, and leads to depression during pregnancy, further reducing the emotional investment and energy devoted to the fetus, that is, poor MFA. Condon indicated that parental psychological variables could affect the MFA quality. Moreover, attachment avoidance-related deactivation strategies are associated with depression maintenance [14]. In fact, when perceiving positive emotional information, people with high attachment avoidance are unable to experience positive emotions; to avoid the activation of the attachment system, they tend to deactivate their emotional channels and hide their feelings [60]. People with a high level of avoidance are less willing to be parents and feel more pressure to raise children [61]. It seems that adult attachment avoidance and the prenatal depression score both affect the mother's intimate connection with the unborn fetus. Another study involving high-risk pregnant women also showed that higher types of avoidant attachment were associated with a lower quality of maternal-fetal bonding. However, inconsistently, in our findings, when depressive symptoms were entered into the regression model, the effect of avoiding attachment was no longer significant [62]. The possible reasons are related to the different samples selected. Therefore, the relationship among these three variables needs to be further studied during different pregnancy periods and in different subgroups of pregnant women in the future. However, no mediating role of the prenatal depression score was observed in the relationship between adult attachment anxiety and the MFA quality, and a previous study demonstrated that caregivers with a higher degree of avoidance are less responsive than those with a lower degree of avoidance [63]. The MFA quality is related to the mental health of mothers, whereas the MFA intensity is not associated with mental health [64]. Existing research has also suggested that future research should focus on the dimensions of MFA.
Our results revealed the relationship between adult attachment avoidance and the prenatal depression score and their effects on the degree of emotional communication and interaction between the mother and the fetus, further providing a basis for understanding the development of maternal-fetal relationships. Therefore, to improve the MFA of pregnant women, we can start from the personality characteristics of pregnant women, such as screening for insecure attachment or high avoidance attachment during antenatal examinations and promoting a positive model for pregnant women to target others and themselves. In addition, for pregnant women with poor mental health, such as high depression scores, family members can increase their social support and health care institutions should popularize knowledge regarding pregnancy to reduce the negative effects of pregnancy. Studies have also noted that by determining the mother's attachment style and MFA status during pregnancy, the early detection of these problems provides an opportunity for professionals to offer specific support and individualized interventions to improve these interactions [65]. In prenatal screening, the timely detection of low MFA and formulating corresponding interventions can improve the quality of life during pregnancy and childhood [20]. Pregnancy adaptation education can improve not only maternal-fetal attachment but also pregnant women's ability to adapt to pregnancy [66]. Some studies also believe that detecting mental well-being, such as depression symptoms and formulating corresponding interventions can help improve MFA [67]. In addition, it is also important to increase support for pregnant women and raise the attention of society and families to these issues [68]. Culture as a macro factor may affect the level of maternalfetal attachment. The researchers also noted the need to raise awareness of cultural influences when evaluating MFA [69]. In addition, a previous study showed that culture has an influence on the depression and attachment dimension [70]. In the future, we need to explore maternal-fetal attachment from the Chinese cultural background perspective, such as the cultural perspective of collectivism with dense social networks and the former onechild policy.

There are some limitations in our study. First, this study was restricted by its cross-sectional design, and we did not track postpartum depression and mother-infant attachment, which should be evaluated in the next steps of our work. Second, given that all data were evaluated at the measurement point, directional and causal conclusions cannot be drawn directly given this design. Moreover, the data collection was based on convenience sampling; thus, our participants may not represent the general pregnant population. In addition, all participants were in the third trimester of pregnancy; thus, the results obtained in this particular group may not easily 
generalize to pregnant women of other gestational weeks. Pregnant women of other gestational weeks need to be included in future studies.

Despite these limitations in our research, our findings provide new insight into understanding the mother-fetal relationship before childbirth and might be effective in providing guidance for prenatal psychological education and individualized interventions.

\section{Abbreviations}

EPDS: Edinburgh Postpartum Depression Scale; ECR: Experience of Close Relationship; MAAS: Maternal Antenatal Attachment Scale; MFA: Maternalfetal attachment; Cl: Confidence interval

\section{Supplementary Information}

The online version contains supplementary material available at https://doi. org/10.1186/s12884-021-03779-5

Additional file 1. General Demographic Information Questionnaire.

\section{Acknowledgements}

We would like to profoundly thank all pregnant women who participated in this study and the medical staff in the antenatal clinic of the Chaohu Hospital of Anhui Medical University for their cooperation.

\section{Authors' contributions}

The manuscript was designed and written by LZ and KZ. The data were collected by LZ and LW; analyzed by LZ, QY, SC, and $\mathrm{CH}$; and verified by $X Z$. All authors read and approved the final manuscript.

\section{Funding}

This study was supported by the National Natural Science Foundation of China (81801341) and the Anhui Provincial Key R\&D Programme (202004j07020030). These funds were only used to provide a small amount of financial compensation to each research participant participating in the research.

\section{Availability of data and materials}

All data supporting our findings are presented in the manuscript; the datasets used and/or analyzed during the current study are available from the corresponding author upon reasonable request.

\section{Declarations}

Ethics approval and consent to participate

The ethics committee of Chaohu Hospital of Anhui Medical University approved the study protocol. All participating pregnant women signed an informed consent form.

\section{Consent for publication}

All participants agreed to record and publish anonymous data.

\section{Competing interests}

The authors do not have potential conflicts of interest to report.

\section{Author details}

${ }^{1}$ School of Mental Health and Psychological Sciences, Anhui Medical University, Hefei 238000, China. ${ }^{2}$ Chaohu Hospital, Anhui Medical University, Hefei 238000, China.

Received: 29 November 2020 Accepted: 30 March 2021 Published online: 16 April 2021

\section{References}

1. Mu TY, Li YH, Pan HF, Zhang L, Zha DH, Zhang CL, et al. Postpartum depressive mood (PDM) among Chinese women: a meta-analysis. Arch
Womens Mental Health. 2019;22(2):279-87. https://doi.org/10.1007/s00737018-0885-3.

2. Woody CA, Ferrari AJ, Siskind DJ, Whiteford HA, Harris MG. A systematic review and meta-regression of the prevalence and incidence of perinatal depression. J Affect Disord. 2017;219:86-92. https://doi.org/10.1016/j.jad.201 7.05.003.

3. Gelaye B, Rondon MB, Araya R, Williams MA. Epidemiology of maternal depression, risk factors, and child outcomes in low-income and middleincome countries. Lancet Psychiatry. 2016;3(10):973-82. https://doi.org/10.1 016/S2215-0366(16)30284-X.

4. Castro e Couto T, Brancaglion MY, Cardoso MN, Faria GC, Garcia FD, Nicolato $\mathrm{R}$, et al. Suicidality among pregnant women in Brazil: prevalence and risk factors. Arch Womens Mental Health. 2016:19(2):343-8.

5. Mbawa M, Vidmar J, Chingwaru C, Chingwaru W. Understanding postpartum depression in adolescent mothers in Mashonaland Central and Bulawayo provinces of Zimbabwe. Asian J Psychiatr. 2018;32:147-50. https:// doi.org/10.1016/j.ajp.2017.11.013.

6. Smith MV, Shao L, Howell H, Lin H, Yonkers KA. Perinatal depression and birth outcomes in a healthy start project. Matern Child Health J. 2011;15(3): 401-9. https://doi.org/10.1007/s10995-010-0595-6.

7. Pesonen AK, Lahti M, Kuusinen T, Tuovinen S, Villa P, Hämäläinen $\mathrm{E}$, et al. Maternal prenatal positive affect, depressive and anxiety symptoms and birth outcomes: the PREDO study. PLoS One. 2016;11(2):e0150058. https:// doi.org/10.1371/journal.pone.0150058.

8. Lahti M, Savolainen K, Tuovinen S, Pesonen AK, Lahti J, Heinonen K, et al. Maternal Depressive Symptoms During and After Pregnancy and Psychiatric Problems in Children. J Am Acad Child Adolescent Psychiatry. 2017;56(1): 30-9 e37.

9. Alhusen JL, Gross D, Hayat MJ, Rose L, Sharps P. The role of mental health on maternal-fetal attachment in low-income women. J Obstetric Gynecol Neonatal Nurs. 2012;41(6):E71-81. https://doi.org/10.1111/j.1552-6909.2012 01385.x.

10. McFarland J, Salisbury AL, Battle CL, Hawes K, Halloran K, Lester BM. Major depressive disorder during pregnancy and emotional attachment to the fetus. Arch Womens Mental Health. 2011;14(5):425-34. https://doi.org/10.1 007/s00737-011-0237-z.

11. Binda V, Figueroa-Leigh F, Olhaberry M. Antenatal and postnatal depressive symptoms: association with quality of mother-infant interaction. Infant Behav Dev. 2019;57:101386. https://doi.org/10.1016/j.infbeh.2019.101386.

12. Alhusen JL. A literature update on maternal-fetal attachment. J Obstetric Gynecol Neonatal Nurs. 2008;37(3):315-28. https://doi.org/10.1111/j.15526909.2008.00241.x

13. Reading AE, Cox DN, Sledmere CM, Campbell S. Psychological changes over the course of pregnancy: a study of attitudes toward the fetus/neonate. Health Psychology. 1984;3(3):211-21. https://doi.org/10.1037/02786133.3.3.211

14. Petri E, Palagini L, Bacci O, Borri C, Teristi V, Corezzi C, et al. Maternal-foetal attachment independently predicts the quality of maternal-infant bonding and post-partum psychopathology. J Maternal Fetal Neonatal Med. 2018; 31(23):3153-9. https://doi.org/10.1080/14767058.2017.1365130.

15. Maddahi MS, Dolatian M, Khoramabadi M, Talebi A Correlation of maternalfetal attachment and health practices during pregnancy with neonatal outcomes. Electron Physician. 2016;8(7):2639-44. https://doi.org/10.19082/2639.

16. Arguz Cildir D, Ozbek A, Topuzoglu A, Orcin E, Janbakhishov CE. Association of prenatal attachment and early childhood emotional, behavioral, and developmental characteristics: a longitudinal study. Infant Ment Health J. 2020;41(4):517-29. https://doi.org/10.1002/imhj.21822.

17. Göbel A, Barkmann C, Arck P, Hecher K, Schulte-Markwort M, Diemert A, et al. Couples' prenatal bonding to the fetus and the association with one's own and partner's emotional well-being and adult romantic attachment style. Midwifery. 2019;79:102549. https://doi.org/10.1016/j.midw.2019.102549.

18. de Cock ES, Henrichs J, Vreeswijk CM, Maas AJ, Rijk CH, van Bakel HJ. Continuous feelings of love? The parental bond from pregnancy to toddlerhood. J Fam Psychol. 2016;30(1):125-34. https://doi.org/10.1037/fa m0000138.

19. Yarcheski A, Mahon NE, Yarcheski TJ, Hanks MM, Cannella BL. A metaanalytic study of predictors of maternal-fetal attachment. Int J Nurs Stud. 2009:46(5):708-15. https://doi.org/10.1016/j.jinurstu.2008.10.013.

20. Čèsnaitè $G$, Domža $G$, Ramašauskaitè $D$, Volochovič J, Bužinskienė D. Factors affecting the maternal-foetal relationship. Acta medica Lituanica. 2019:26(2): 118-24. https://doi.org/10.6001/actamedica.v26i2.4032. 
21. Pisoni C, Garofoli F, Tzialla C, Orcesi S, Spinillo A, Politi P, et al. Risk and protective factors in maternal-fetal attachment development. Early Hum Dev. 2014;90(Suppl 2):S45-6. https://doi.org/10.1016/S0378-3782(14)50012-6.

22. Bowlby J. The making and breaking of affectional bonds. I. Aetiology and psychopathology in the light of attachment theory. An expanded version of the Fiftieth Maudsley Lecture, delivered before the Royal College of Psychiatrists, 19 November 1976. Br J Psychiatry. 1977;130(3):201-10. https:// doi.org/10.1192/bjp.130.3.201.

23. Chrzan-Dętkoś M, Łockiewicz M. Maternal romantic attachment, and antenatal and postnatal mother-infant attachment in a sample of polish women. Eur J Dev Psychol. 2015;12(4):429-42. https://doi.org/10.1080/174 05629.2015.1036024.

24. Jones JD, Cassidy J, Shaver PR. Parents' self-reported attachment styles: a review of links with parenting behaviors, emotions, and cognitions. Personality Soc Psychol Rev. 2015;19(1):44-76. https://doi.org/10.1177/1 088868314541858.

25. Monk C, Leight KL, Fang Y. The relationship between women's attachment style and perinatal mood disturbance: implications for screening and treatment. Arch Womens Mental Health. 2008;11(2):117-29. https://doi.org/1 0.1007/s00737-008-0005-X.

26. Daglar G, Nur N. Level of mother-baby bonding and influencing factors during pregnancy and postpartum period. Psychiatr Danub. 2018;30(4):43340. https://doi.org/10.24869/psyd.2018.433.

27. Huang $\mathrm{YL}$, Chen $\mathrm{SH}$, Tseng $\mathrm{HH}$. Attachment avoidance and fearful prosodic emotion recognition predict depression maintenance. Psychiatry Res. 2019; 272:649-54. https://doi.org/10.1016/j.psychres.2018.12.119.

28. Nakamura Y, Okada T, Morikawa M, Yamauchi A, Sato M, Ando M, et al. Perinatal depression and anxiety of primipara is higher than that of multipara in Japanese women. Sci Rep. 2020;10(1):17060. https://doi.org/10.1 038/s41598-020-74088-8.

29. Shorey S, Chan SW, Chong YS, He HG. Maternal parental self-efficacy in newborn care and social support needs in Singapore: a correlational study. J Clin Nurs. 2014;23(15-16):2272-82. https://doi.org/10.1111/jocn.12507.

30. Nonnenmacher N, Noe D, Ehrenthal JC, Reck C. Postpartum bonding: the impact of maternal depression and adult attachment style. Arch Womens Mental Health. 2016;19(5):927-35. https://doi.org/10.1007/s00737-016-0648-y.

31. ISH, JEH, Assis C, Kovo M. POSTPARTUM BONDING DIFFICULTIES AND ADULT ATTACHMENT STYLES: THE MEDIATING ROLE OF POSTPARTUM DEPR ESSION AND CHILDBIRTH-RELATED PTSD. Infant Ment Health J. 2018;39(2): $198-208$.

32. Cox JL, Holden JM, Sagovsky R. Detection of postnatal depression. Development of the 10-item Edinburgh postnatal depression scale. Br J Psychiatry. 1987;150(6):782-6. https://doi.org/10.1192/bjp.150.6.782.

33. Lau Y, Wang Y, Yin L, Chan KS, Guo X. Validation of the mainland Chinese version of the Edinburgh postnatal depression scale in Chengdu mothers. Int J Nurs Stud. 2010;47(9):1139-51. https://doi.org/10.1016/j.jinurstu.2010.02.005.

34. Chen C, Gao J, Zhang J, Jia L, Yu T, Zheng Y. Serum leptin level measured $48 \mathrm{~h}$ after delivery is associated with development of postpartum depressive symptoms: a 3-month follow-up study. Arch Womens Mental Health. 2016;19(6):1001-8. https://doi.org/10.1007/s00737-016-0647-z.

35. Su KP, Chiu TH, Huang CL, Ho M, Lee CC, Wu PL, et al. Different cutoff points for different trimesters? The use of Edinburgh postnatal depression scale and Beck depression inventory to screen for depression in pregnant Taiwanese women. Gen Hosp Psychiatry. 2007;29(5):436-41. https://doi. org/10.1016/j.genhosppsych.2007.05.005.

36. Shi P, Ren H, Li H, Dai Q. Maternal depression and suicide at immediate prenatal and early postpartum periods and psychosocial risk factors. Psychiatry Res. 2018;261:298-306. https://doi.org/10.1016/j.psychres.2017.12.085.

37. Brennan KA, Clark CL, Shaver PR. Self-report measurement of adult attachment: An integrative overview. In: Simpson JA, Rholes WS, editors. Attachment theory and close relationships. New York: The Guilford Press; 1998. p. 46-76.

38. Fraley RC, Waller NG, Brennan KA. An item response theory analysis of selfreport measures of adult attachment. J Pers Soc Psychol. 2000;78(2):350-65. https://doi.org/10.1037/0022-3514.78.2.350.

39. Li T, Kato K. Measuring adult attachment: Chinese adaptation of the ECR scale. Acta Psychol Sin. 2006;38(3):399-406.

40. Xu W, Fu Z, He L, Schoebi D, Wang J. Growing in times of grief: attachment modulates bereaved adults' posttraumatic growth after losing a family member to cancer. Psychiatry Res. 2015;230(1):108-15. https://doi.org/10.101 6/j.psychres.2015.08.035.
41. Condon JT. The assessment of antenatal emotional attachment: development of a questionnaire instrument. Br J Med Psychol. 1993;66(Pt 2): 167-83. https://doi.org/10.1111/j.2044-8341.1993.tb01739.x.

42. GN, HXF. Validity and Reliability of the Chinese Version Maternal Antenatal Attachment Scale. Chinese J Clin Psychol. 2017;25(004):675-7.

43. Golbasi Z, Ucar T, Tugut N. Validity and reliability of the Turkish version of the maternal antenatal attachment scale. Japan J Nurs Sci. 2015;12(2):15461. https://doi.org/10.1111/jjns.12052.

44. Hayes AF. Introduction to mediation, moderation, and conditional process analysis: a regression-based approach, vol. New York: Guilford Press; 2013.

45. Li Y, Zeng Y, Zhu W, Cui Y, Li J. Path model of antenatal stress and depressive symptoms among Chinese primipara in late pregnancy. BMC Pregnancy Childbirth. 2016;16(1):180. https:/doi.org/10.1186/s12884-016-0972-2.

46. Brittain K, Myer L, Koen N, Koopowitz S, Donald KA, Barnett W, et al. Risk factors for antenatal depression and associations with infant birth outcomes: results from a south African birth cohort study. Paediatr Perinat Epidemiol. 2015;29(6):505-14. https://doi.org/10.1111/ppe.12216.

47. Golbasi Z, Kelleci M, Kisacik G, Cetin A. Prevalence and correlates of depression in pregnancy among Turkish women. Matern Child Health J. 2010;14(4):485-91. https://doi.org/10.1007/s10995-009-0459-0.

48. van de Loo KFE, Vlenterie R, Nikkels SJ, Merkus P, Roukema J, Verhaak CM, et al. Depression and anxiety during pregnancy: The influence of maternal characteristics. Birth (Berkeley, Calif). 2018;45(4):478-89.

49. de la Fe Rodríguez-Muñoz M, Le HN, de la Cruz IV, Crespo MEO, Méndez NI. Feasibility of screening and prevalence of prenatal depression in an obstetric setting in Spain. Eur J Obstet Gynecol Reprod Biol. 2017;215:101-5.

50. Ashley JM, Harper BD, Arms-Chavez CJ, LoBello SG. Estimated prevalence of antenatal depression in the US population. Arch Womens Mental Health. 2016;19(2):395-400. https://doi.org/10.1007/s00737-015-0593-1.

51. Mikulincer M, Shaver PR. Attachment in adulthood: structure, dynamics, and change. In: Attachment Theory \& Close Relationships; 2007.

52. Zdolska-Wawrzkiewicz A, Chrzan-Dętkoś M, Bidzan M. Maternal attachment style during pregnancy and becoming a mother in Poland. J Reprod Infant Psychol. 2018;36(1):4-14. https://doi.org/10.1080/02646838.2017.1395400.

53. Ayers $S$, Jessop D, Pike A, Parfitt $Y$, Ford E. The role of adult attachment style, birth intervention and support in posttraumatic stress after childbirth: a prospective study. J Affect Disord. 2014;155:295-8. https://doi.org/10.1016/ j.jad.2013.10.022

54. Selcuk E, Günaydin G, Sumer N, Harma M, Salman S, Hazan C, et al. Selfreported romantic attachment style predicts everyday maternal caregiving behavior at home. J Res Pers. 2010;44(4):544-9. https://doi.org/10.1016/j.jrp.2 010.05.007.

55. Walsh J, Hepper EG, Marshall BJ. Investigating attachment, caregiving, and mental health: a model of maternal-fetal relationships. BMC Pregnancy Childbirth. 2014;14(1):383. https://doi.org/10.1186/s12884-014-0383-1.

56. Mikulincer M, Florian V. Maternal-fetal bonding, coping strategies, and mental health during pregnancy-the contribution of attachment style. J Soc Clin Psychol. 1999;18(3):255-76. https://doi.org/10.1521/jscp.1999.18.3.255.

57. Green BL, Furrer C, MCAllister C. How do relationships support parenting? Effects of attachment style and social support on parenting behavior in an at-risk population. Am J Community Psychol. 2007;40(1-2):96-108. https:// doi.org/10.1007/s10464-007-9127-y.

58. Feeney BC, Collins NL. Motivations for caregiving in adult intimate relationships: influences on caregiving behavior and relationship functioning. Personality Soc Psychol Bull. 2003;29(8):950-68. https://doi.org/1 $0.1177 / 0146167203252807$

59. Leerkes EM, Supple AJ, O'Brien M, Calkins SD, Haltigan JD, Wong MS, et al. Antecedents of maternal sensitivity during distressing tasks: integrating attachment, social information processing, and psychobiological perspectives. Child Dev. 2015;86(1):94-111. https://doi.org/10.1111/cdev.12288.

60. White LO, Wu J, Borelli JL, Rutherford HJ, David DH, Kim-Cohen J, et al. Attachment dismissal predicts frontal slow-wave ERPs during rejection by unfamiliar peers. Emotion (Washington, DC). 2012;12(4):690-700.

61. Rholes WS, Simpson JA, Friedman M. Avoidant attachment and the experience of parenting. Personality Soc Psychol Bull. 2006:32(3):275-85. https://doi.org/10.1177/0146167205280910.

62. Røhder K, Væver MS, Aarestrup AK, Jacobsen RK, Smith-Nielsen J, Schiøtz ML. Maternal-fetal bonding among pregnant women at psychosocial risk: the roles of adult attachment style, prenatal parental reflective functioning, and depressive symptoms. PLoS One. 2020;15(9):e0239208. https://doi.org/1 0.1371/journal.pone.0239208. 
63. Feeney BC, Collins NL. Predictors of caregiving in adult intimate relationships: an attachment theoretical perspective. J Pers Soc Psychol. 2001;80(6):972-94. https://doi.org/10.1037/0022-3514.80.6.972.

64. Condon JT, Corkindale C. The correlates of antenatal attachment in pregnant women. Br J Med Psychol. 1997;70(Pt 4):359-72. https://doi.org/1 0.1111/j.2044-8341.1997.tb01912.x

65. Tabaehemami S, Nouri A, Malekpour M, Abedi A. Effectiveness of cognitivebehavior training for mothers on changing maternal behavior and Child's insecure attachment. J Clin Psycol. 2011;3:7-16.

66. Baghdari N, Sadeghi Sahebzad E, Kheirkhah M, Azmoude E. The effects of pregnancy-adaptation training on maternal-fetal attachment and adaptation in pregnant women with a history of baby loss. Nurs Midwifery Stud. 2016; 5(2):e28949. https://doi.org/10.17795/nmsjournal28949.

67. Ozcan H, Ustundag MF, Yilmaz M, Aydinoglu U, Ersoy AO, Eyi EGY. The relationships between prenatal attachment, basic personality traits, styles of coping with stress, depression, and anxiety, and marital adjustment among women in the third trimester of pregnancy. Eurasian J Med. 2019;51(3):2326. https://doi.org/10.5152/eurasianjmed.2019.15302.

68. Delavari M, Mirghafourvand M, Mohammad-Alizadeh-Charandabi S. The relationship of maternal-fetal attachment and depression with social support in pregnant women referring to health centers of Tabriz-Iran, 2016. J Maternal Fetal Neonatal Med. 2018;31(18):2450-6.

69. Kuo PC, Bowers B, Chen YC, Chen CH, Tzeng YL, Lee MS. Maternal-foetal attachment during early pregnancy in Taiwanese women pregnant by in vitro fertilization. J Adv Nurs. 2013;69(11):2502-13. https://doi.org/10.1111/ jan.12135.

70. Gündüz E, Juen BH, Geser W, Ayer A, Deisenhammer EA. Cultural differences concerning depressive disorders and attachment dimensions. Neuropsychiatr. 2018;32(4):204-13.

\section{Publisher's Note}

Springer Nature remains neutral with regard to jurisdictional claims in published maps and institutional affiliations.

Ready to submit your research? Choose BMC and benefit from:

- fast, convenient online submission

- thorough peer review by experienced researchers in your field

- rapid publication on acceptance

- support for research data, including large and complex data types

- gold Open Access which fosters wider collaboration and increased citations

- maximum visibility for your research: over $100 \mathrm{M}$ website views per year

At $\mathrm{BMC}$, research is always in progress.

Learn more biomedcentral.com/submissions 